Int. J. Dev. Biol. 62: 387-391 (2018)

https://doi.org/10.1387/ijdb.180049fs

\title{
Elly Tanaka's passion for exploring animal regeneration
}

\author{
NADIA MERCADER ${ }^{1}$ and FLORENCI SERRAS ${ }^{*, 2}$ \\ ${ }^{1}$ Institute of Anatomy, University of Bern, Bern, Switzerland and \\ ${ }^{2}$ Department of Genetics, Institute of Biomedicine (IBUB), University of Barcelona, Barcelona, Spain
}

\begin{abstract}
This interview, performed by the guest editors of this Int. J. Dev. Biol. Special Issue on Regeneration, narrates the story of Elly M. Tanaka on her regeneration research journey. The main goal is to get a glimpse of the thoughts and scientific history of this leading figure in regeneration biology. In addition to her scientific history, we will learn about her captivating determination to ask relevant questions in science and her use of animal models for solving complex problems.
\end{abstract}

KEY WORDS: interviere, scientific history, axolotl, limb regeneration, spinal cord regeneration

Most of our current knowledge about regeneration biology is mainly the product of two strategies. The first is the availability of animal models that, even knowing that sometimes are distant from humans, help to search for universal mechanisms. The second, is the capacity to design sophisticated engineered tools that help to explore some of these mechanisms in animal models, by addressing gene function and cellular behaviour. Elly Tanaka has succeeded in both, and her results represent a paradigm in regeneration research (Tanaka and Reddien, 2011).

Elly Tanaka's research has had an enormous impact on our current understanding of regeneration. Her favorite model is the axolotl or Mexican salamander Ambystoma mexicanum. Her group focuses on limb and spinal cord regeneration to understand the role of cell plasticity, pattern formation and the molecular signals triggering a regenerative response (Tanaka, 2016). She described the origin of regenerating limb tissues and unravelled the molecular mechanisms underlying pattern formation, necessary for blastema cells to get positional information to enable regeneration of the proper limb segment. Her group also described that adult neural stem cells can dedifferentiate to embryonic neural stem cells in order to reconstruct a damaged spinal cord. Moreover, her team performed a challenging screening assay that led to the identification of a pro-regenerative molecule. She co-headed the axolotl genome sequencing project (Nowoshilow et al., 2018), that represents a breakthrough and will allow to fully exploit new genome editing technologies in this species, know to be the champion of regeneration. With the conviction that knowledge of salamander regeneration fuels the design of novel regenerative strategies in mammals, Elly's team is also creating 3D-spinal cord and retinal tissues from mouse and human embryonic stem cells.

Elly Tanaka received her B.A. in Biochemistry at Harvard University in 1987 and her PhD in 1993 at the University of California, San Francisco, under the supervision of Prof. Marc W. Kirschner. She was a postdoctoral fellow from 1994-1999 at the laboratory of Jeremy P. Brockes, University College of London, where she started her studies on salamander limb regeneration. In 1999 she moved to the Max Planck Institute for Molecular Cell Biology and Genetics Dresden, where she consolidated her own group. In 2008 she became Full Professor of Animal Models of Regeneration at the DFG Research Center for Regenerative Therapies, at the Technische Universität Dresden, where she became director from 2014 to 2016. In 2017 she moved to the Research Institute of Molecular Pathology (IMP) at the Vienna BioCenter in Vienna (Austria).

\section{How did you get into science?}

Growing up, I was kind of an all-around student but was always grounded in math and chemistry. In University I started out in Chemistry, but then considered Comparative Literature at one point. But science seemed like a more concrete way of looking at the world and an easier way to make what you liked to do as a profession. I got hooked when I performed my Bachelor's thesis studying microtubule-associated proteins in Drosophila in Larry Goldstein's laboratory. I performed genetics, and the beauty of seeing phenotypes like white and red eyes segregate was just so amazing. Then, I basically stopped going to classes and really enjoyed the feeling of doing my own project. So I decided to give graduate school applications a try.

\footnotetext{
*Address correspondence to: Nadia Mercader. Institute of Anatomy, University of Bern, Bern, Switzerland. e-mail: nadia.mercader@ana.unibe.ch web http://www.anaweb.ch/research/developmental_biology_and_regeneration/group_members/detail/index_eng.php?id=449 - Fax: +41 316313807.

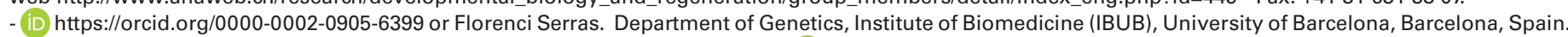
e-mail: fserras@ub.edu - web: http://www.ub.edu/developmentalbiology/web - iD https://orcid.org/0000-0003-1184-5386
} 


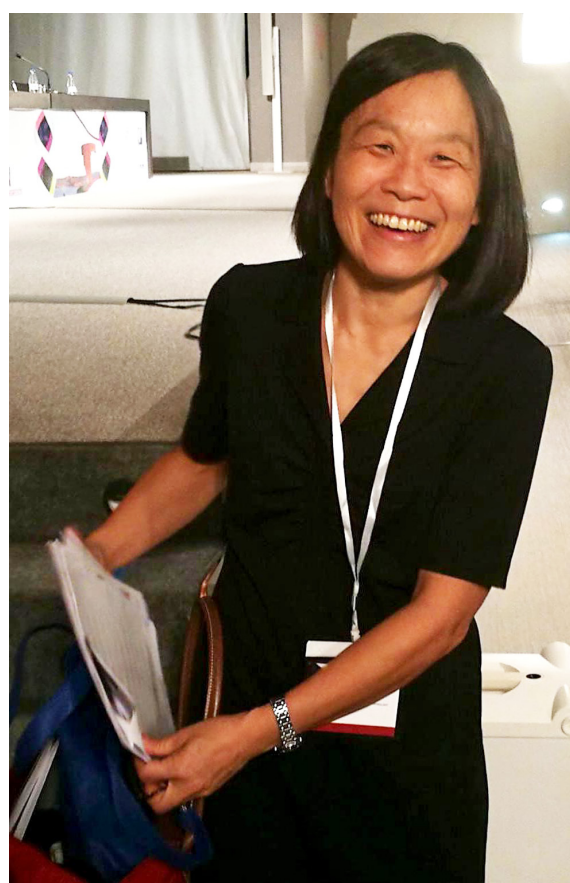

Fig. 1. Elly M. Tanaka after her plenary lecture during the Joint Meeting ofThe Spanish societies of Genetics (SEG), Developmental Biology (SEBD) and Cell Biology (SEBC), held in Gijón (Spain), 24-27th October 2017.

Why did you choose regeneration as your research topic? And why did the axolotl become your favorite animal model?

In graduate school I was working on the role of microtubules in axonal guidance using Xenopus laevis as a system. However, I was always interested in embryology and particularly fascinated by the problem of embryonic regulation-how removal of a large part of the embryo is compensated to make a normal organism. As I started to think about post-doctoral training, I was encouraged to think about unsolved problems. When I was reading, I bumped into the regeneration literature and it somehow satisfied my interest in how missing parts are detected and restored. I also thought that one day a potential medical relevance would also be interesting. As a post-doctoral fellow, I worked on Notophthalmus viridescens, but frankly I found the system a little frustrating because regeneration was very slow and one used animals caught from the wild, so there was a lot of variability coming from many unknowns. So, when I started my lab, I switched to the axolotl, which was being bred in the axolotl colony in Bloomington Indiana at that time. I really wanted to establish live imaging in regeneration, and the availability of pigmentless axolotls, and the ability to work with larvae was important. It has turned out to be a great system for transgenesis, which was also one of my goals to make the system experimentally accessible.

\section{Who were the people that inspired you during your scientific career?}

From reading the literature, I was inspired by Ross Granville Harrison, who showed that axons grew out from the cell by establishing cell culture from amphibian embryos. He also did very important and elegant work defining the limb field. I was also inspired by Santiago Ramon y Cajal who made so many important observations about the nervous system. I was of course also inspired by Hans Spemann's organizer experiment. Somehow the aesthetic part of science - the beauty of biology and the pleasure in a beautiful experiment are important to me.

My PhD supervisor, Marc Kirschner, had a profound influence on me. He always emphasized working on an important question, and not being afraid to develop new methods to try to understand complex phenomena. Also, as a graduate student, mentorship and discussions with Tim Mitchison and Andrew Murray were so inspiring. Again, I think all of those people really loved science and a beautiful experiment.

\section{What do you consider to be the most significant advances in the field of regeneration since you started?}

I think our ability to examine regeneration at the cellular level rather than tissue scale events has been very important. I also think that the ability to use molecular genetics to test molecular function has also been very important. With these two attributes, a number of essential questions in regeneration have been better clarified such as the potency of cells, some of the molecular triggers of regeneration, and some of the molecules directing growth and patterning.

\section{Could you share with us some of your eureka moments?}

Martin Kragl had been attempting to examine molecular plasticity of blastema cells by combining cell tracing via GFP transgenics with single cell profiling (very early on!). In parallel, Dunja Knapp was developing methods to track nerves and Schwann cells in order to study their role in regeneration. As we started examining the animals, we started to realize the restrictions in cell potential during regeneration and became really excited (Kragl et al., 2009). Re-examining the experiments in which irradiated limbs were rescued with nerve tissue, and figuring out which cells were really rescuing the limbs was a pinnacle of this effort that was so beautiful to see with these new tools.

Seeing Takuji Sugiura's expression clone a molecule that functions in regeneration, and seeing all of his analysis on the

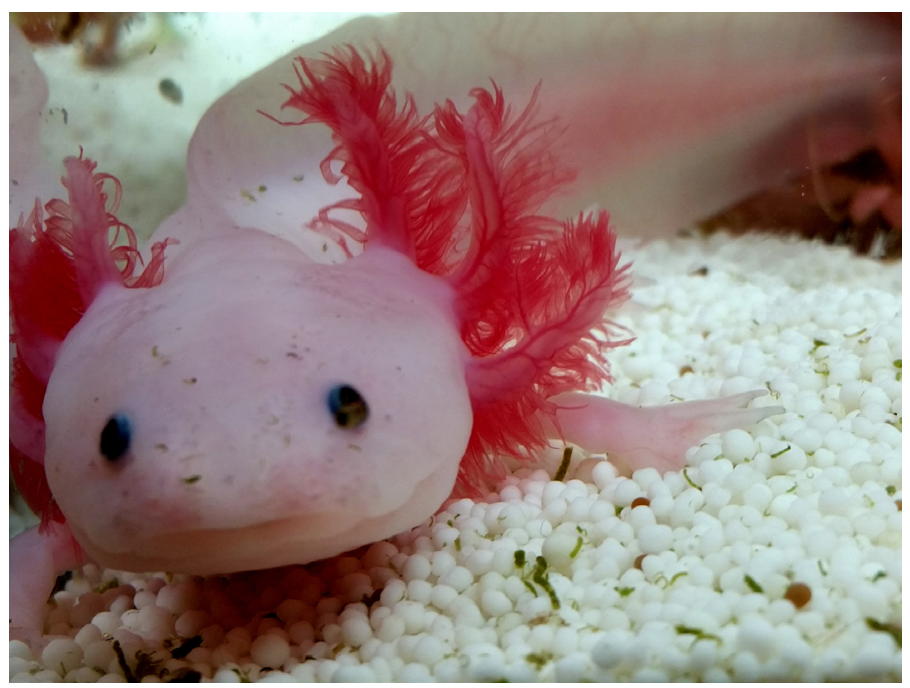

Fig. 2. The axolotl Ambystoma mexicanum. A model system in animal regeneration. 

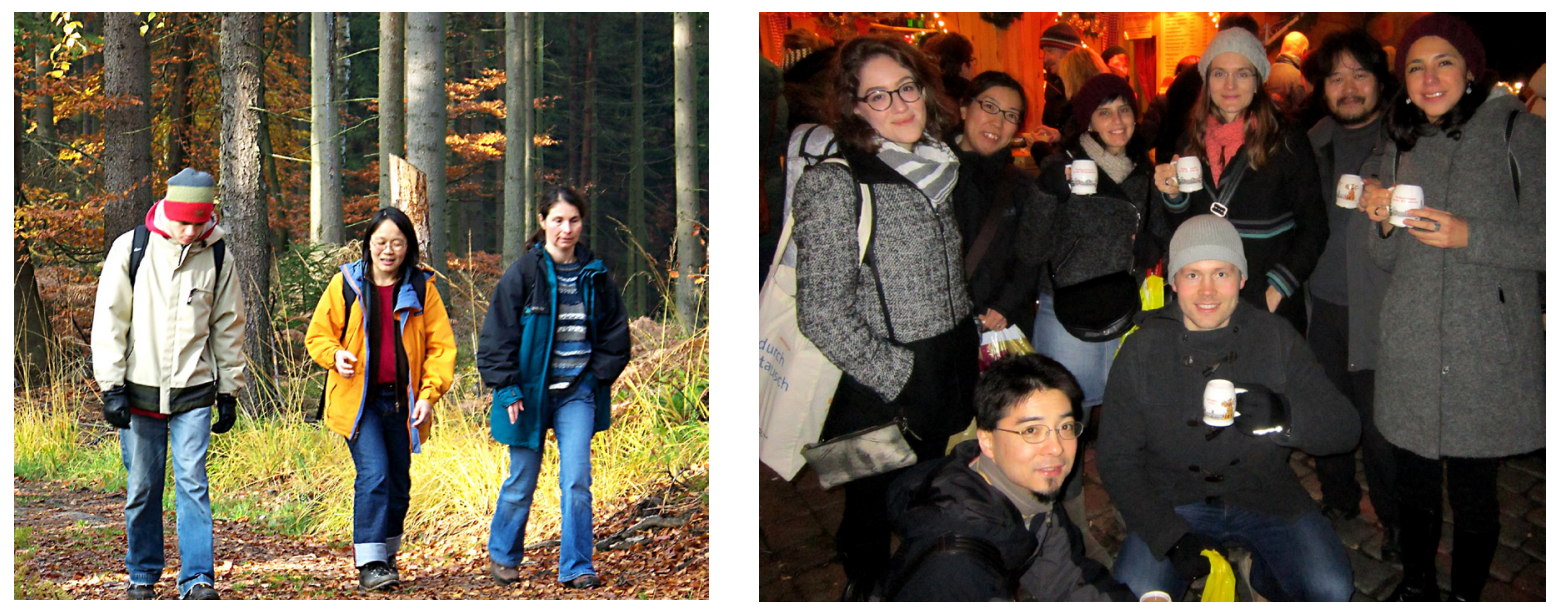

Fig. 3 (Left). Walking and talking science in Saxon Switzerland in 2007. Eugen Nacu and Dunja Knapp contributed to showing the lineage restriction of blastema cells in Kragl et al., 2009. Eugen Nacu together with Elena Gromberg (not shown) defined anterior and posterior morphogens required for limb regeneration (Nacu et al., 2016).

Fig. 4 (Right). At the Dresden Medieval Christmas Market in 2015. Bottom left, Takuji Sugiura (Sugiura et al., 2016), Upper right, Tatiana SandovalGuzman (Sandoval-Guzmán et al., 2014), to her left, Akira Tazaki (Roensch et al., 2013).

extracellular function, and development of the in vivo testing was also amazing (Sugiura et al., 2016). He just came to my office week after week with new results and it was such a pleasure to think about the important questions and the experimental approaches to take to answer them. It just gave me a bubbly feeling.

Similarly, Eugen Nacu deciding to take up the question of how anterior and posterior cells interact led to a similarly exciting situation-just seeing the Smoothened agonist-induced limbs and then discussing with Eugen and Elena Gromberg their results and how to further dissect the system was a true pleasure (Nacu et al., 2016).

\section{Many organisms regenerate better or solely during juvenile stages. Is regeneration to some extent recapitulating embryonic development?}

The more we examine regenerating cells at the molecular level, the more it is clear that to a large part embryonic development is recapitulated with some adjustments during regeneration, at least by the time the blastema is established and patterning mechanisms are acting. However, the establishment of the blastema seems to be distinct from embryonic development.

Blastema cells were thought to be multipotent cells that rebuilt the limb. Yet you demonstrated a higher degree of lineage restriction than previously anticipated. Do you think that all cells within a given tissue are equally able to dedifferentiate and contribute to regeneration? Would you describe that population as some kind of "stem cell pool"?

Based on the kinetics of blastema formation compared to the axolotl cell cycle length and also on Josh Currie's movies of digit tip regeneration I believe most if not all cells in certain tissues have the competence to become regenerative. That is certainly the case for SOX2 $2^{+}$spinal cord cells, which wholesale translocate into the regenerating tissue. In the case of non-epithelial cells such as fibroblasts some cells seem to remain behind but the question is whether this reflects a transient restriction of cell migration potential, or whether these cells are truly unable to become a blastema cell if they did not migrate into the appropriate area.

\section{What are your thoughts on how a regenerating limb knows when to stop growing?}

I guess that coordination between existing tissues with the regenerating one is needed to tell cells when to stop so that the size of the regenerate matches the body.

\section{And how does the blastema know which part of the limb needs to be regenerated?}

In terms of the patterning, I think that cells in different parts of the limb have intrinsic molecular programs that tell them where they are from. For example, Nadia Mercader and Miguel Torres revealed the role of Meis homeodomain proteins in upper arm identity (Mercader et al., 1999). An interesting question is whether "intrinsic" is truly cell intrinsic, or whether like planaria, long-range differences in extracellular signalling molecules could dictate under homeostatic conditions, positional cell identity.

According to you, what are the key questions related to regeneration that are still unsolved? Where do you think the field of regeneration is heading?

Well - I think you defined one major one-no one really knows how regeneration stops and how size is matched with the body.

I also think there is still very little known about the cell intrinsic programs that are involved in converting a cell sitting in the mature tissue into a blastema cell.

Finally, I think that it is unknown how the genome is organized to hold mature cells in a "waiting but ready" state for regeneration, and whether such a state exists in mammals. I do think that the field is heading toward trying to use the knowledge from regeneration model organisms to understand the evolution of regeneration and how to "fix" regeneration in other animals. The recent work from Didier Stainier's lab comparing zebrafish and medaka heart 


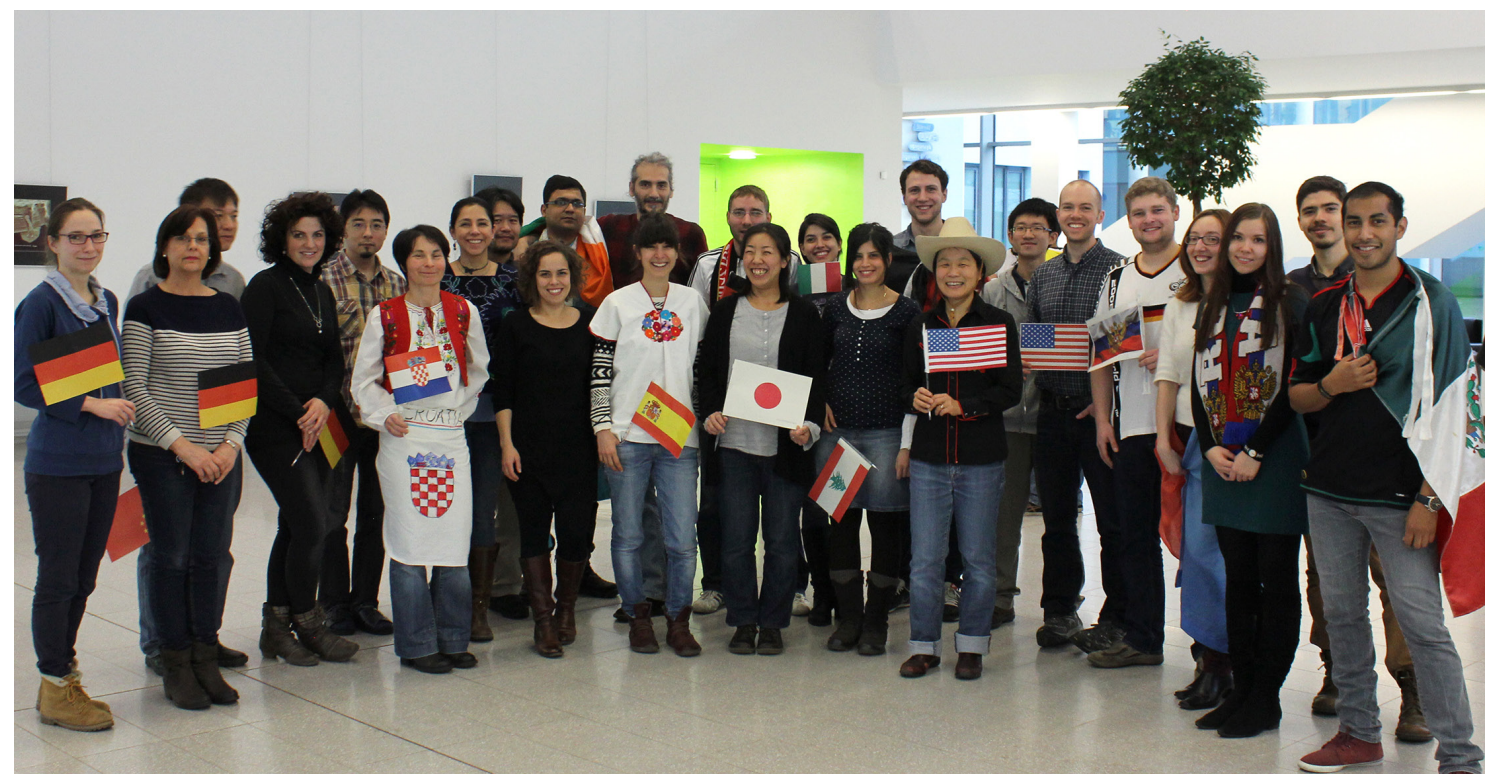

Fig. 5. The multicultural Tanaka lab at the DFG Research Center for Regenerative Therapies, Technische Universität Dresden in 2015.

regeneration and the immune system is a nice example (Lai et al., 2017).

\section{After several decades of research with different animal models: can we conclude that there are common mechanisms of regeneration?}

I think the maintenance of embryonic patterning cues or the capability to re-active them, is at least a conceptual commonality. Whether the specific genes/instances in the different organisms represents a true evolutionary conservation at the genome level is rather unknown and maybe even unlikely.

\section{How do you see animal models in regeneration research for the coming years?}

I think it is an exciting time for animal models of regeneration due to the new availability of gene-editing tools. This will provide highly refined methods of tracing cells and perturbing gene function that will be exciting for many. I think that because of this, we will see regeneration being studied in a wider variety of organisms and species. This will make the comparative approaches more realistic and will lead to some interesting surprises I guess.

We often hear the term "from bench to bedside" but equally important is the reverse direction from "bedside to bench". Do you think that a closer interaction between clinicians and basic researchers would be profitable?

I certainly think that clinicians and basic scientists can work together well and can learn from each other. Medical and research educations lead to people thinking in different ways about the same phenomenon. We have worked with clinicians in the past and they have been fascinated by the regeneration system and strive to make the connection between the wonder of what they see in the animals and how to bridge the gap in humans. In future I do believe that the link between concepts coming from regenerative models to human regenerative medicine will be made.
Do you have any advice for junior scientists trying to establish their own labs?

I think the most important advice is to be not afraid to do something different or hard. I think, rightfully, that many young scientists worry about publishing in a reasonable amount of time, and equate this with the need to something akin to low hanging fruit. I do think it is possible to design a project aiming at something bigger, but with small steps in between that allow publication. I also think that young scientists should have faith that good, rigorous science is appreciated, and this should be the primary goal.

l'd just like to say what a pleasure it has been to interact over the years with regeneration colleagues working in all kinds of different systems. For me regeneration is interesting because it is a field that acknowledges differences. These differences will finally be able to be studied in more depth in the future. Looking forward to a great future for regeneration research!

\section{References}

KRAGL M, KNAPP D, NACU E, KHATTAK S, MADEN M, EPPERLEIN HH, TANAKA EM (2009). Cells keep a memory of their tissue origin during axolotl limb regeneration. Nature 460: 60-65.

LAI SL, MARÍN-JUEZ R, MOURA PL, KUENNE C, LAI JKH, TSEDEKE AT, GUENTHER S, LOOSO M, STAINIER DY. Reciprocal analyses in zebrafish and medaka reveal that harnessing the immune response promotes cardiac regeneration. eLife 2017 Jun 20;6. pii: e25605.

MERCADER N, LEONARDO E, AZPIAZU N, SERRANO A, MORATA G, MARTíNEZ C, TORRES M (1999). Conserved regulation of proximodistal limb axis development by Meis $1 / \mathrm{Hth}$. Nature 402: 425-429.

NACU E, GROMBERG E, OLIVEIRA CR, DRECHSEL D, TANAKA EM (2016). FGF8 and SHH substitute for anterior-posterior tissue interactions to induce limb regeneration. Nature 533: 407-410.

NOWOSHILOW S, SCHLOISSNIG S, FEI J-F, DAHL A, PANG AWC, PIPPEL M, WINKLER S, HASTIE AR, YOUNG G, ROSCITO JG, FALCON F, KNAPP D, POWELL S, CRUZ A, CAO H, HABERMANN B, HILLER M, TANAKA EM, MYERS EW (2018). The axolotl genome and the evolution of key tissue formation regulators. Nature 554: 50-55. 
ROENSCH K, TAZAKI A, CHARA O, TANAKA EM (2013). Progressive specification rather than intercalation of segments during limb regeneration. Science 342: 1375-1379.

SANDOVAL-GUZMÁN T, WANG H, KHATTAK S, SCHUEZ M, ROENSCH K, NACU E, TAZAKIA, JOVEN A, TANAKA EM, SIMONA (2014). Fundamental Differences in Dedifferentiation and Stem Cell Recruitment during Skeletal Muscle Regeneration in Two Salamander Species. Cell Stem Cell 14: 174-187.
SUGIURA T, WANG H, BARSACCHI R, SIMON A, TANAKA EM (2016). MARCKSlike protein is an initiating molecule in axolotl appendage regeneration. Nature 531: 237-240.

TANAKA EM (2016). The Molecular and Cellular Choreography of Appendage Regeneration. Cell 165: 1598-1608.

TANAKA EM, REDDIEN PW (2011). The cellular basis for animal regeneration. Dev Cell 21: 172-185. 


\section{Further Related Reading, published previously in the Int. J. Dev. Biol.}

Planaria: an animal model that integrates development, regeneration and pharmacology Oné R. Pagán

Int. J. Dev. Biol. (2017) 61: 519-529

https://doi.org/10.1387/ijdb.160328op

The pioneer factor Smed-gata456-1 is required for gut cell differentiation and maintenance in planarians Alejandro González-Sastre, Nídia De Sousa, Teresa Adell and Emili Saló

Int. J. Dev. Biol. (2017) 61: 53-63

https://doi.org/10.1387/ijdb.160321es

ITRAQ-based proteomic analysis of adaptive response in the regenerating limb of the Cynops orientalis newt Xiao-Fang Geng, Jian-Lin Guo, Xia-Yan Zang, Jing-Yan Sun, Peng-Fei Li, Fu-Chun Zhang and Cun-Shuan Xu Int. J. Dev. Biol. (2015) 59: 487-496

https://doi.org/10.1387/ijdb.150363cx

Reptile genomes open the frontier for comparative analysis of amniote development and regeneration Marc Tollis, Elizabeth D. Hutchins and Kenro Kusumi

Int. J. Dev. Biol. (2014) 58: 863-871

https://doi.org/10.1387/ijdb.140316kk

The dynamics of alkaline phosphatase activity during operculum regeneration in the polychaete Réka Szabó and David E.K. Ferrier

Int. J. Dev. Biol. (2014) 58: 635-642

https://doi.org/10.1387/ijdb.140116df

Regeneration in spiralians: evolutionary patterns and developmental processes Alexandra E. Bely, Eduardo E. Zattara and James M. Sikes

Int. J. Dev. Biol. (2014) 58: 623-634

https://doi.org/10.1387/ijdb.140142ab

Segment formation in Annelids: patterns, processes and evolution Guillaume Balavoine

Int. J. Dev. Biol. (2014) 58: 469-483

https://doi.org/10.1387/ijdb.140148gb

Interstitial stem cells in Hydra: multipotency and decision-making Charles N. David

Int. J. Dev. Biol. (2012) 56: 489-497

https://doi.org/10.1387/ijdb.113476cd

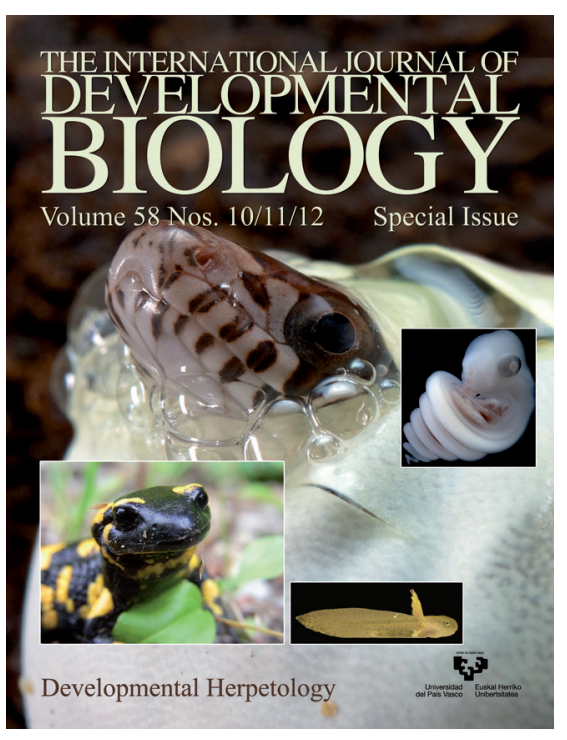

5 yr ISI Impact Factor $(2016)=2.421$
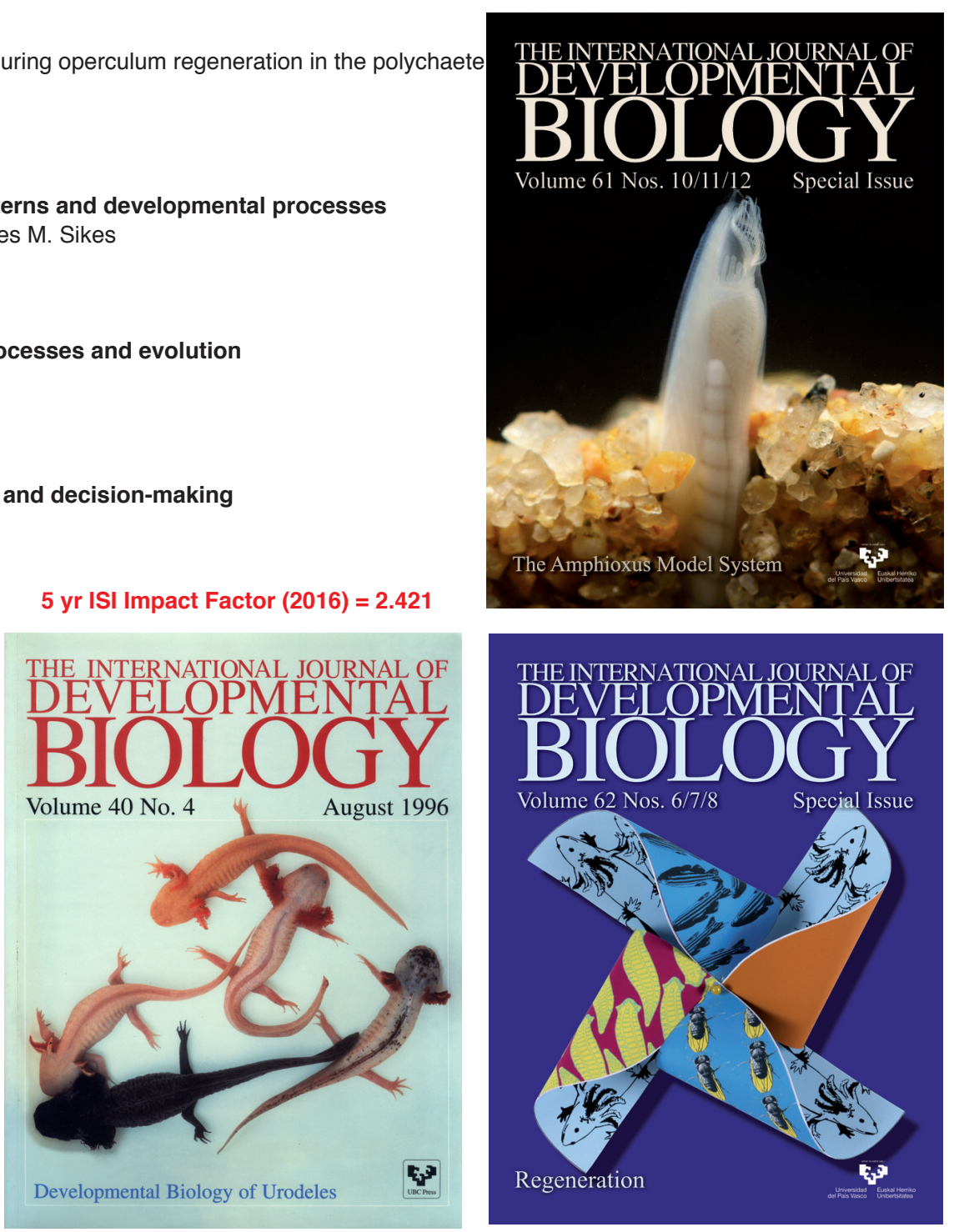